\title{
Levothyroxine Treatment of Euthyroid Children with Autoimmune Hashimoto Thyroiditis: Results of a Multicenter, Randomized, Controlled Trial
}

\author{
Helmuth G. Dörr ${ }^{\mathrm{a}}$ Markus Bettendorf ${ }^{\mathrm{b}}$ Gerhard Binder ${ }^{\mathrm{c}}$ Beate Karges ${ }^{\mathrm{d}}$ \\ Carolin Kneppo ${ }^{\text {b }}$ Heinrich Schmidt ${ }^{\mathrm{e}}$ Egbert Voss $^{\mathrm{f}}$ Martin Wabitsch ${ }^{\mathrm{g}}$ \\ Jörg Dötsch ${ }^{\mathrm{h}}$ \\ ${ }^{a}$ Division of Paediatric Endocrinology and Diabetes, Department of Paediatrics, University of Erlangen, Erlangen, \\ ${ }^{b}$ Division of Paediatric Endocrinology and Diabetes, Department of Paediatrics, University of Heidelberg, \\ Heidelberg, 'Paediatric Endocrinology, University Children's Hospital, University of Tübingen, Tübingen, ${ }^{\mathrm{d} D i v i s i o n}$ \\ of Endocrinology and Diabetes, Medical Faculty, RWTH Aachen University, Aachen, ePaediatric Endocrinology, \\ Dr. von Haunersches Kinderspital, University of Munich, Munich, ${ }^{\mathrm{f}} \mathrm{Cnopf}$ 'sche Kinderklinik, Nuremberg, ${ }^{\mathrm{g}}$ Division \\ of Paediatric Endocrinology and Diabetes, Department of Paediatrics, University of Ulm, Ulm, and hepartment of \\ Paediatrics, University of Cologne, Cologne, Germany
}

\section{Key Words}

Levothyroxine treatment · Euthyroid children · Hashimoto thyroiditis

\begin{abstract}
Background: Levothyroxine (L-T4) treatment of euthyroid children with Hashimoto thyroiditis (HT) is a controversial issue. Patients and Methods: We conducted a prospective, randomized, controlled clinical trial. Out of 79 identified euthyroid patients, 59 started the study; 25 patients ( $21 \mathrm{fe}-$ male, 4 male; age: $11.8 \pm 2.3$ years) received L-T4 at a mean dose of $1.6 \mu \mathrm{g} / \mathrm{kg}(\mathrm{SD}, 0.8)$ daily, and 34 (27 female, 7 male; age: $12.6 \pm 1.2$ years) were not treated. Patients developing subclinical hypothyroidism during follow-up $(n=13)$ were treated with L-T4 and removed from the observation group. As the main outcome measures, thyroid gland volume (determined by ultrasound) as well as serum levels of TSH, free T4, and antibodies against thyroid peroxidase and thyro-
\end{abstract}

globulin were assessed every 6 months for 36 months. Results: At the start, the mean thyroid volume (standard deviation score, SDS) was 2.5 in the treatment group and 1.6 in the observation group. There was a constant decline in mean thyroid volume (SDS) from 2.13 (month 12) to 1.12 (month 30) in the treated group, with a delta thyroid volume of -1.01 SDS. In the observation group, the mean delta thyroid volume increased to +0.27 SDS. The change of the delta thyroid volume was statistically significantly different between both groups during the 12- and 30-month time points $(p<0.05)$. L-T4 had no effect on thyroid function and serum thyroid antibodies. Conclusions: L-T4 treatment can decrease the thyroid volume in euthyroid children with HT, but the effect is limited to a definite time period.

(c) 2015 S. Karger AG, Basel

Presented in part at the 9th Joint Meeting of Paediatric Endocrinology 2013 in Milan, Italy.

\section{KARGER 125}

(c) 2015 S. Karger AG, Base

$1663-2818 / 15 / 0844-0266 \$ 39.50 / 0$

E-Mail karger@karger.com

www.karger.com/hrp
Helmuth G. Dörr, MD

Division of Paediatric Endocrinology, Department of Paediatrics

Friedrich-Alexander University Erlangen-Nürnberg

Loschgestrasse 15, DE-91054 Erlangen (Germany)

E-Mail helmuth-guenther.doerr@uk-erlangen.de 


\section{Introduction}

Hashimoto's thyroiditis (HT) is the most common acquired thyroid disease in children and adolescents [1-3]. At the time of diagnosis, children and adolescents may be asymptomatic or may be referred with goiter and/or hypothyroid symptoms [4-6]. Diagnosis is based on the presence of antibodies against thyroid peroxidase (TPOAb) and/or thyroglobulin (TgAb) and characteristic sonographic features such as diffuse glandular enlargement with coarse, heterogeneous and hypoechoic parenchymal echo pattern $[2,7-9]$.

The clinical course of the disease is highly variable. There is no doubt that patients with overt hypothyroidism should receive treatment with levothyroxine (L-T4). It has been shown that L-T4 treatment of hypothyroid patients with HT also causes a reduction in the thyroid gland volume $[10,11]$. However, there is still controversy as to whether children with subclinical hypothyroidism (particularly those with normal serum free T4 (fT4) and TSH concentrations $<10 \mathrm{mU} / \mathrm{l}$ ) should be electively treated with L-T4 $[5,12,13]$, while there is no clear-cut recommendation for the treatment of euthyroid children with HT. Rother et al. [14] found an unchanged thyroid size in all children and adolescents treated with L-T4, and a study from Thailand demonstrated that euthyroid children with HT had normal growth and puberty without L-T4 [10]. The decision whether to treat or not to treat euthyroid children with HT should also consider the natural course of the disease. It has been shown that $64.8 \%$ of a group of 105 euthyroid children with HT who were not treated with L-T4 still remained euthyroid after 5 years of follow-up [15]. Studies in euthyroid adults with HT showed reduced serological and cellular markers of autoimmune thyroiditis after short-term prophylactic treatment [16] and a reduction in the thyroid gland volume [17].

The aim of the present study is to determine the effects of L-T4 on various parameters such as thyroid gland volume, thyroid antibodies, as well as TSH and fT4 levels in euthyroid subjects with HT. Therefore, we designed a prospective, randomized, open, controlled clinical trial at 10 tertiary care centers for pediatric endocrinology in Bavaria and Baden-Württemberg, Germany.

\section{Patients and Methods}

\section{Patients}

The study started at 10 centers [Augsburg, Erlangen, Heidelberg, Munich (2), Nuremberg, Stuttgart, Tübingen, Ulm, and Würzburg] in January, 2002, and was terminated in December,
2009. Our intention was to study 120 euthyroid HT patients, 60 with L-T4 and 60 without L-T4, during an observation period of 60 months. However, for various reasons, e.g. insufficient recruitment of patients by participating centers (only 6 out of 10 centers provided patients), noncompliance, incomplete data and documentation, the overall aims of the study were not achieved, and the study was terminated earlier. Inclusion criteria were children and adolescents aged 2-18 years, positive TPOAb and/or $\mathrm{TgAb}$, euthyroid function, normal thyroid size or goiter with distinct sonographic features of HT, and the patients' and parents' written informed consent. Exclusion criteria were current treatment with L-T4, type 1 diabetes, positive serum antibodies against TSH receptor, Turner or Down syndrome, and severe illness. Dropout criteria were noncompliance, withdrawal of consent, and L-T4 discontinuation for more than 2 weeks. The study protocol was approved by the Ethical Committee of the University of Erlangen and local institutional review boards, and the study was conducted in accordance with the Declaration of Helsinki.

\section{Study Protocol}

We used an individually randomized, 2-group, parallel trial as study design. The euthyroid patients with HT were identified locally and reported to the study center in Erlangen where the random allocation sequence was generated and the enrolled participants were assigned to the treatment group with L-T4 or to the observation group without treatment (fig. 1).

The thyroid volume was determined by ultrasound in each participating center. All investigators were uniformly instructed about the definition of the measuring points before the start of the study. Thyroid-lobe height, width, and depth were examined with a $7.5-\mathrm{MHz}$ linear transducer in transverse and longitudinal scans, and the volume of each thyroid lobe was calculated using the formula proposed by Brunn et al. [18] by multiplying the height, width, and thickness with 0.479 . The thyroid volume was defined as the sum of the volumes of both lobes. The total thyroid volume was calculated in standard deviation score (SDS) values using published reference data from the German KIGGS study where thyroid volume was determined in 6- to 17-year-old children and adolescents $(n=9,175)$ by ultrasonography $[19,20]$. The following formula was used:

(measured thyroid volume - mean thyroid volume value of the reference population)/SD value of the reference population.

Patients were considered to be goitrous if they had a thyroid volume $>2.0$ SDS.

L-T4 was given once daily p.o. in the morning, starting with a dose of $50 \mu \mathrm{g}$ for patients with a body weight $<50 \mathrm{~kg}, 75 \mu \mathrm{g}$ for individuals with a body weight between 50 and $75 \mathrm{~kg}, 100 \mu \mathrm{g}$ for patients with a body weight between 75 and $100 \mathrm{~kg}$, and $150 \mu \mathrm{g}$ for patients with a body weight $>100 \mathrm{~kg}$. The calculated L-T4 dose (mean $\pm \mathrm{SD}$ ) was $1.6 \pm 0.8 \mu \mathrm{g} / \mathrm{kg}$. If necessary, the $\mathrm{L}-\mathrm{T} 4$ dose was adjusted to keep the TSH values within the desired range (0.5-4 $\mathrm{mU} / \mathrm{l})$. Accordingly, the L-T4 dose was decreased in 4 patients and increased in 5 individuals. The baseline data of 59 euthyroid patients with HT (observation group: $\mathrm{n}=34$; treatment group: $\mathrm{n}=$ 25 ) are shown in table 1. During the study, after an average of 14.7 months, 13 individuals (mean age: 11.8 years) in the observation group showed subclinical hypothyroidism (TSH $>6 \mathrm{mU} / \mathrm{l}$; normal fT4) and were treated with L-T4 (group 3 in table 1). Their data were excluded from further calculation. 
Table 1. Clinical and laboratory data of the 59 euthyroid patients with HT at the start of the study (groups 1 and 2)

\begin{tabular}{lccc}
\hline & $\begin{array}{c}\text { Group 1 } \\
(\mathrm{n}=34 ; 27 \text { female, } 7 \text { male })\end{array}$ & $\begin{array}{l}\text { Group 2 } \\
(\mathrm{n}=25 ; 21 \text { female, 4 male) }\end{array}$ & $\begin{array}{c}\text { Group 3 } \\
(\mathrm{n}=13 ; 10 \text { female, 3 male })\end{array}$ \\
\hline Chronological age, years & $12.6 \pm 2.4(4.8-17.2)$ & $11.8 \pm 2.3(7.7-15.4)$ & $11.8 \pm 2.1(4.8-17.2)$ \\
Height, SDS & $0.02 \pm 1.02$ & $0.36 \pm 1.2$ & $0.2 \pm 1.2$ \\
BMI & $19.3 \pm 3.5$ & $19.0 \pm 3.1$ & $18.0 \pm 2.5$ \\
BMI, SDS & $0.05 \pm 1.1$ & $0.2 \pm 0.9$ & $-0.2 \pm 1.1$ \\
L-T4 dosage, $\mu \mathrm{g} / \mathrm{kg} /$ day & - & $1.6 \pm 0.8$ & $1.5 \pm 0$ \\
TSH, mU/l & $3.0 \pm 1.5$ & $3.0 \pm 1.3$ & $6.5 \pm 1.7$ \\
fT4, pg/ml & $13.5 \pm 2.8$ & $12.4 \pm 2.2$ & $11.6 \pm 2.5$ \\
TPOAb, U/ml & $1,057 \pm 957$ & $825 \pm 1,015$ & $2,073 \pm 1,073$ \\
TgAb, U/ml & $445 \pm 753$ & $545 \pm 788$ & $265 \pm 244$ \\
Total thyroid volume, $\mathrm{ml}$ & $10.8 \pm 5.6$ & $11.3 \pm 6.6$ & $11.6 \pm 5.0$ \\
Thyroid volume, SDS & $1.6 \pm 2.1$ & $2.5 \pm 2.8$ & $2.4 \pm 3.2$ \\
Thyroid volume $\geq 2$ SDS, \% & 24 & 47 & 30
\end{tabular}

Data are shown as means \pm SD. Group $1=$ Observation group; group 2 = treatment group; group 3 = patients who became hypothyroid during the study. ${ }^{a} \mathrm{fT} 4 \mathrm{pg} / \mathrm{ml} \times 1.28=\mathrm{pmol} / \mathrm{l}$.

Fig. 1. Study design and assignment of 79 euthyroid patients with HT who were randomized to receive either L-T4 treatment or no treatment. $\mathrm{R}=$ Randomization. * Thirteen patients who became hypothyroid were removed from the study and treated with L-T4.

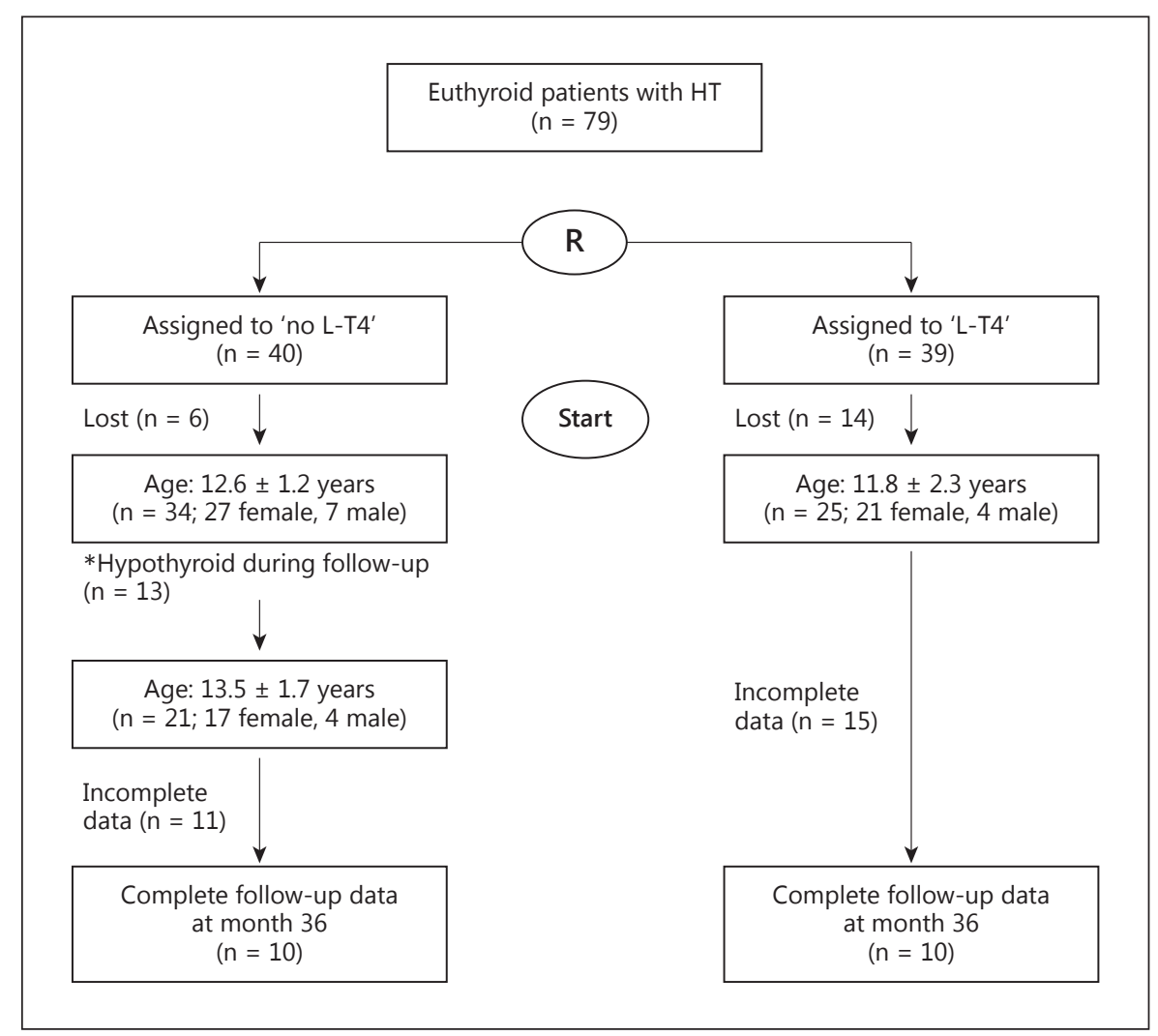

The clinical and laboratory assessment including clinical examination, ultrasound of the thyroid gland, measurement of thyroid hormones, and organ-specific autoantibodies (as specified below) was performed at baseline and every 6 months until month 60 . However, when the study was stopped after 8 years, 36 months' follow-up data were available in only 10 patients from each group. Since the evaluation of thyroid volume change might depend on the time points chosen, we decided to use the 30-month time point. The data at the 36-month time point could be biased due to the small number of patients and the loss of data of 6 patients. 
Table 2. Longitudinal changes in auxological parameters, thyroid hormones, autoantibody levels, and thyroid volumes of the 10 patients in each group who completed the study at baseline and after 12, 24, and 36 months (mean \pm SD)

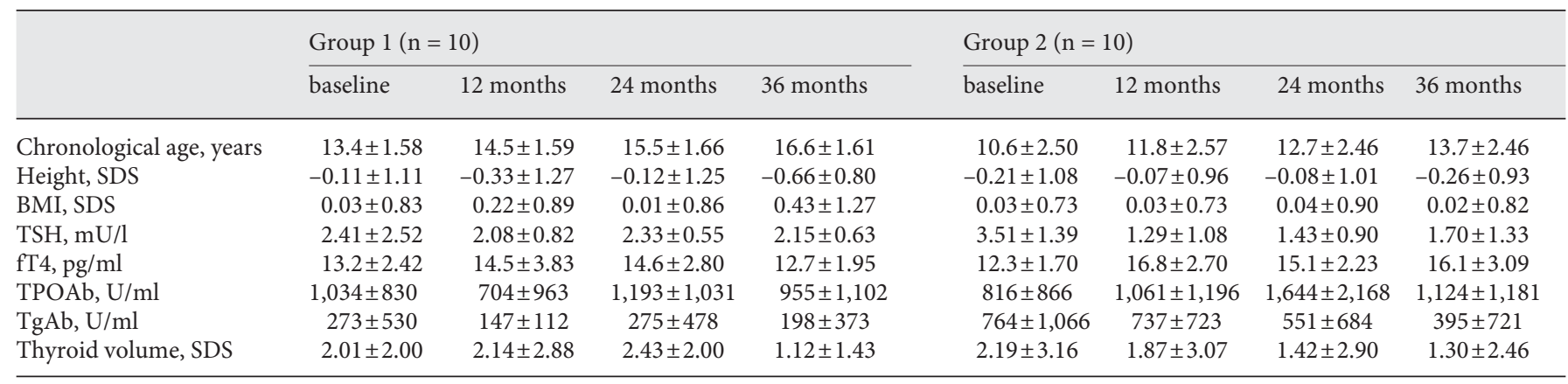

Data are shown as means \pm SD. Group $1=$ Observation group; group $2=$ treatment group.

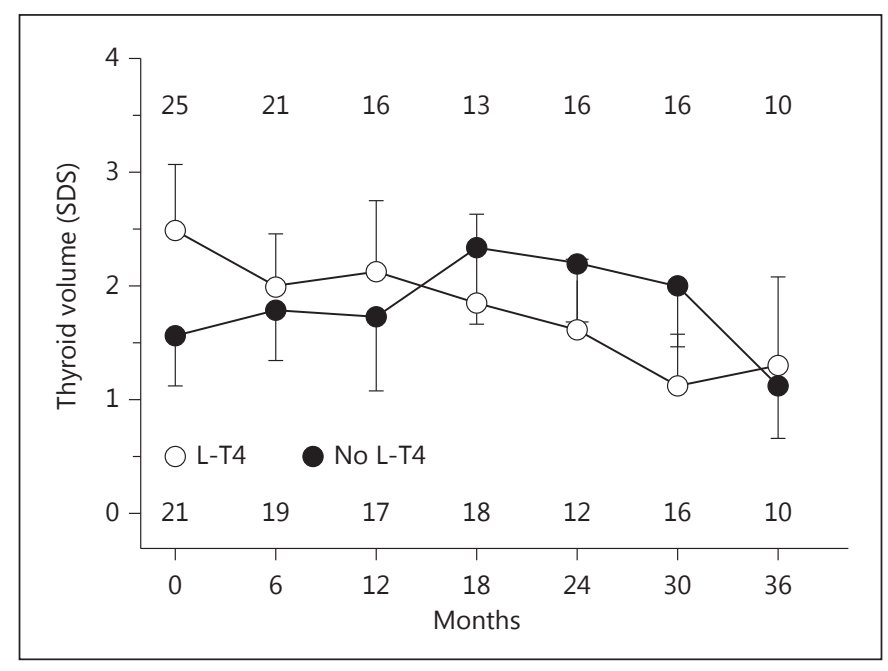

Fig. 2. Thyroid volume SDS (mean \pm SE) in euthyroid children with HT. At the start of the study: $\mathrm{n}=46$ patients; at the end of the study: $\mathrm{n}=20$ patients. Open circles: treatment group with L-T4; closed circles: comparison group without L-T4. The numbers of patients in each group at the different examination points are shown above or below the SDS values.

For calculation of height and BMI SDS values, we used the German reference data of Kromeyer-Hauschild et al. [21].

\section{Main Outcome Measures}

Changes in thyroid gland volume (as determined by ultrasound), and changes in serum levels of TSH, thyroid hormones, TPOAb, and TgAb were assessed every 6 months for 36 months.

\section{Laboratory Measurements}

$\mathrm{TSH}, \mathrm{fT} 4$, and serum thyroid autoantibodies (TPOAb and TgAb) were determined using commercial immunometric reagent kits in each center. The following reference intervals were used: TSH $(0.4-$ $4.5 \mathrm{mU} / \mathrm{l})$, fT4 (10-23 pmol/l), TPOAb (<60 U/l), and TgAb (<60 U/l).

\section{Statistical Analysis}

Parameters were compared between the treatment group and observation group using the Mann-Whitney U exact test. The dynamics of TSH, fT4, or thyroid volume in each group were calculated with nonparametric ANOVA for repeated measurements (Friedman test). All analyses involved two-tailed tests of significance and were performed using SPSS software (version 20; IBM, Germany). p values $<0.05$ were considered to be statistically significant.

\section{Results}

\section{Study Population}

Patients with HT presented to the participating centers with clinical symptoms consistent with thyroid dysfunction, a positive family history for HT, or were detected by chance. Data of patients fulfilling the inclusion criteria were sent anonymously to Erlangen, where the randomization process was started. Initially, 79 euthyroid patients with HT were identified, of whom 20 were lost by the first baseline visit. Thus, we were able to include 59 euthyroid patients (48 female, 11 male) with HT in the study (fig. 1). Relevant clinical and laboratory data are shown in table 1 . The mean $( \pm S D)$ chronological age of the patients with HT in the treatment group $(n=25)$ was $11.8 \pm 2.3$ years and thus slightly lower than in the observation group $(n=34)$ where it was $12.6 \pm 2.4$ years. As shown in table 1 , the baseline characteristics of the two groups were not significantly different. The patients who became hypothyroid during the study (group 3) had the same mean chronological age at the start of L-T4 as the patients who were treated from the very beginning of the study. Complete data were available for 10 patients in each group at the last follow-up at 36 months and used for a longitudinal analysis (table 2). 


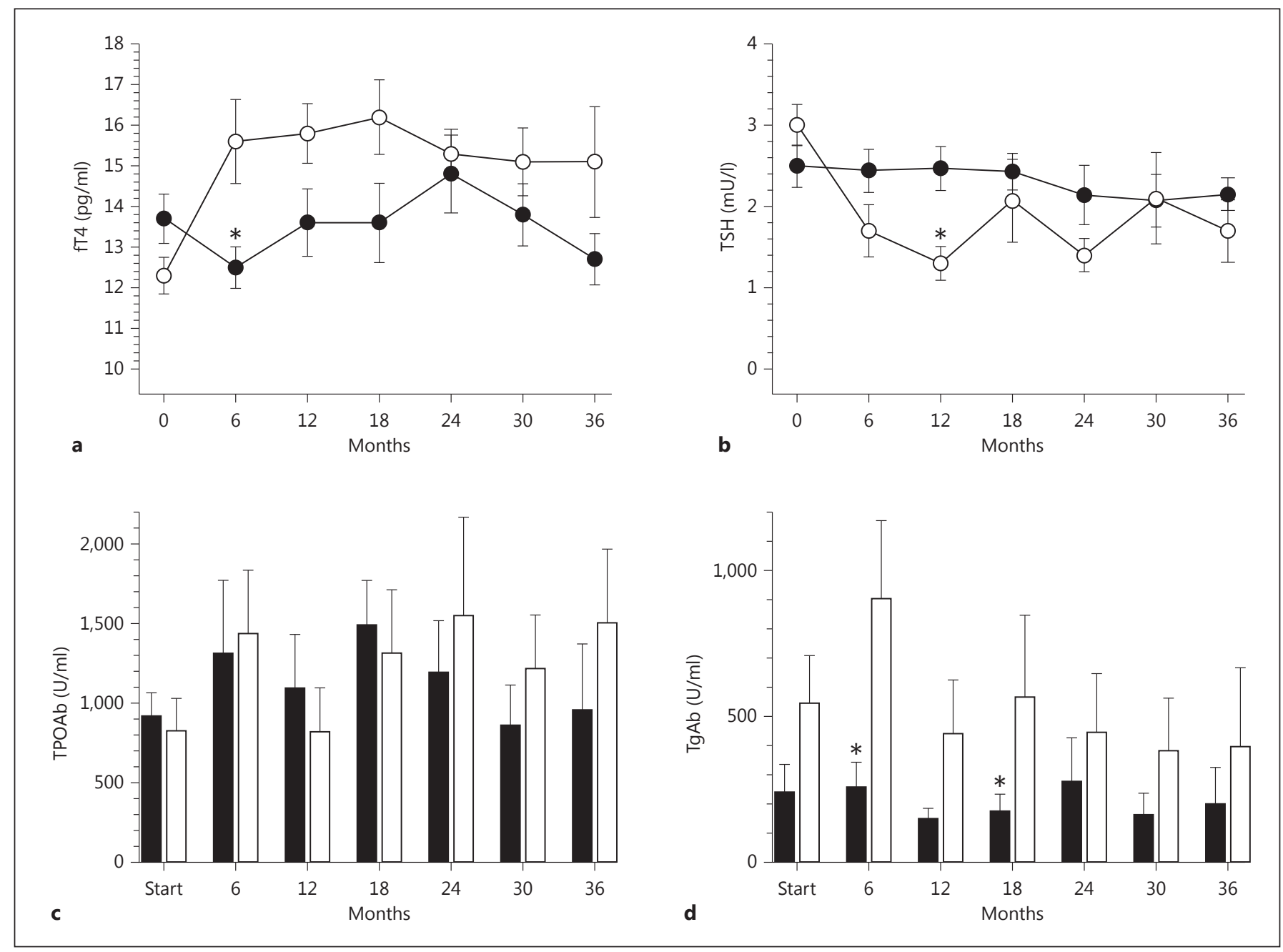

Fig. 3. Serum thyroid hormones (mean \pm SE) and autoantibodies (mean \pm SE) in euthyroid children with HT during the course of the study. The patient numbers at the different examination points are shown in figure 2. a fT4 (pg/ml); fT4 pg/ml × $1.28=$ pmol/l. b TSH $(\mathrm{mU} / \mathrm{l})$. c TPOAb $(\mathrm{U} / \mathrm{ml})$. d TgAb $(\mathrm{U} / \mathrm{ml})$. Open circles/columns: treatment group with L-T4; closed circles/columns: comparison group without L-T4. ${ }^{*} \mathrm{p}<0.05$

\section{Thyroid Volume}

An enlarged thyroid volume $>2.0$ SDS was found at baseline in $47 \%$ of the individuals in the treatment group and in $24 \%$ of the individuals in the observation group. At the start of the study, the mean thyroid volume was slightly higher in the treatment group (2.5 SDS) than in the observation group (1.6 SDS). As shown in figure 2, there was a constant decline in the mean thyroid volume from 2.13 SDS (month 12) to 1.12 SDS (month 30) in the L-T4-treated group. The delta thyroid volume was -1.01 SDS. In the observation group, the mean thyroid volume remained unchanged or slightly increased at the same period from 1.73 to 2.0 SDS, with a delta thyroid volume of
+0.27 SDS. Statistically, the change of the delta thyroid volume was significantly different between both groups during the 12 - and 30 -month time points $(\mathrm{p}<0.05)$. However, comparing the thyroid volume (SDS) between both groups at each time point, we found no statistically significant difference. At the 36-month time point, the mean thyroid volume (SDS) was almost identical in both groups.

\section{Thyroid Function and Autoantibodies}

Serum levels of fT4, TSH, TPOAb, and TgAb are shown in figure 3 . At baseline, there was no difference in serum fT4 and TSH levels between the treatment group 
Table 3. Data from the literature on the effects of L-T4 treatment on the thyroid volume in children and adolescents with HT

\begin{tabular}{|c|c|c|c|c|c|c|c|}
\hline Authors [Ref.], year & $\begin{array}{l}\text { Patients, } \\
\mathrm{n}\end{array}$ & $\begin{array}{l}\text { Age range, } \\
\text { years }\end{array}$ & $\begin{array}{l}\text { Sex ratio, } \\
\text { F:M }\end{array}$ & $\mathrm{L}-\mathrm{T} 4$ & $\begin{array}{l}\text { Study duration, } \\
\text { years }\end{array}$ & $\begin{array}{l}\text { Clinical status } \\
\text { at the start }\end{array}$ & $\begin{array}{l}\text { Reduction of } \\
\text { thyroid size }\end{array}$ \\
\hline Rother et al. [14], 1994 & 69 & $5.2-18.5$ & $5: 1$ & + & $3.6($ mean $)$ & $\begin{array}{l}\mathrm{Eu}+\mathrm{G} \\
\mathrm{SH}+\mathrm{G} \\
\mathrm{Hypo}+\mathrm{G}\end{array}$ & $\begin{array}{l}\text { no } \\
75 \% \text { no; } 25 \% \text { yes } \\
76 \% \text { yes; } 24 \% \text { no }\end{array}$ \\
\hline Jaruratanasirikul et al. [10], 2001 & 46 & $9.0-15.4$ & $14.3: 1$ & + & 5.9 (mean) & $\begin{array}{l}\mathrm{Eu}+\mathrm{G} \\
\mathrm{SH}+\mathrm{G} \\
\mathrm{Hypo}+\mathrm{G}\end{array}$ & $\begin{array}{l}\text { no } \\
\text { no } \\
\text { yes }\end{array}$ \\
\hline Svensson et al. [11], 2006 & 90 & $6.1-17.7$ & 4.3:1 & + & 2.8 (median) & $\begin{array}{l}\mathrm{Eu} \\
\mathrm{Eu}+\mathrm{G} \\
\mathrm{SH} \\
\mathrm{SH}+\mathrm{G} \\
\text { Hypo } \\
\text { Hypo + G }\end{array}$ & $\begin{array}{l}\text { no } \\
\text { yes } \\
\text { yes } \\
\text { yes } \\
\text { yes } \\
\text { yes }\end{array}$ \\
\hline $\begin{array}{l}\text { Karges et al. [25], } 2007 \\
\text { Patients with type } 1 \mathrm{DM}\end{array}$ & 14 & $13.3 \pm 2.1$ & $\begin{array}{l}4: 1 \\
0.75: 1\end{array}$ & + & 2.5 (mean) & $\begin{array}{l}\mathrm{Eu}+\mathrm{G} \\
\mathrm{Eu} \\
\mathrm{Eu} \\
\mathrm{Eu}+\mathrm{G}\end{array}$ & $\begin{array}{l}\text { yes } \\
\text { increase } \\
\text { increase } \\
\text { increase }\end{array}$ \\
\hline Scarpa et al. [24], 2010 & $\begin{array}{l}25 \\
25\end{array}$ & $\begin{array}{l}11.1-13.4 \\
11.1-13.0\end{array}$ & $\begin{array}{l}2.2: 1 \\
4: 1\end{array}$ & $\begin{array}{l}+ \\
-\end{array}$ & $\begin{array}{l}2.0 \\
2.0\end{array}$ & $\begin{array}{l}\mathrm{Eu} \\
\mathrm{Eu}\end{array}$ & $\begin{array}{l}\text { yes } \\
\text { increase }\end{array}$ \\
\hline Özen et al. [5], 2011 & 101 & $12.3 \pm 2.9$ & $5.7: 1$ & $\begin{array}{l}+ \\
-\end{array}$ & 2.0 & $\begin{array}{l}\mathrm{Eu}+\mathrm{G} \\
\mathrm{Eu}+\mathrm{G}\end{array}$ & $\begin{array}{l}\text { yes } \\
\text { no }\end{array}$ \\
\hline
\end{tabular}

+= Treatment with L-T4; - = treatment without L-T4; Eu = euthyroid; $\mathrm{SH}=$ subclinical hypothyroidism; Hypo = overt hypothyroidism; $\mathrm{G}=$ goiter; $\mathrm{DM}=$ diabetes mellitus.

and the observation group. After the start of L-T4 treatment, mean fT4 levels significantly increased from 14.4 to $19.8 \mathrm{pmol} / \mathrm{l}(\mathrm{p}<0.05)$ at month 6 , whereas mean TSH levels significantly declined from $3.0 \mathrm{mU} / \mathrm{ml}$ at the start to $1.3 \mathrm{mU} / \mathrm{ml}(\mathrm{p}<0.05)$ at month 12 . In the observation group without L-T4, both thyroid hormones remained unchanged during the study period. Significant differences between the treatment group and the observation group were found for serum fT4 levels at month 6 and for TSH levels at month 12 (fig. 3). Thyroid antibodies showed a high variability. At baseline, both TPOAb and $\mathrm{TgAb}$ were positive in $80 \%$ of the individuals in the treatment group and in $57 \%$ of those in the observation group. The rate of positive antibodies remained unchanged within both groups during the observation period. Serum $\mathrm{TgAb}$ levels were higher in the treatment group (significant at months 6 and $18 ; \mathrm{p}<0.05)$ than in the observation group throughout the study period (fig. 3 ).

L-T4 Treatment of Euthyroid Children with Autoimmune HT

\section{Longitudinal Data}

The data of the patients with HT that were complete at 36 months $(\mathrm{n}=10)$ were analyzed longitudinally. The mean $( \pm S D)$ age of the patients in the treatment group $(\mathrm{n}=10)$ was $10.6 \pm 2.5$ years, which was lower than in the observation group $(\mathrm{n}=10 ; 13.4 \pm 1.6$ years). The clinical and laboratory characteristics were not different between the two groups except for lower TGAb levels in the observation group. The thyroid hormones and autoantibody levels of the 10 patients in each group at baseline, at 12 and 24 months, and at the last visit were not significantly different (table 2). The longitudinal analysis of the thyroid volume of the patients showed almost identical values at baseline. In the L-T4-treated group, there was a constant decline in the mean thyroid volume from the start to the 24-month time point (delta thyroid volume: -0.77 SDS), whereas the mean thyroid volume remained unchanged or slightly increased in the observation group 
(delta thyroid volume: +0.42 ). The change of the delta thyroid volume was significantly different between both groups from the start to the 24 -month time point $(\mathrm{p}<$ 0.05).

\section{Discussion}

HT is the most common form of autoimmune thyroid disease in children and adolescents (female/male ratio approx. $4-5: 1$ ), with an incidence of $0.1-5 \%$ per 100,000 $[1,2,4]$. At the time of diagnosis, most of the patients are euthyroid $[8,15,22,23]$. Controversy exists as to whether these euthyroid children and adolescents with HT (in particular those with goiter) require L-T4 therapy. There are only few studies in children with HT evaluating changes in thyroid volume (table 3 ) following treatment with L-T4 $[5,10,11,14,24]$. In a retrospective study, the goiter size remained unchanged in all euthyroid patients with HT treated with L-T4 [14]. Svensson et al. [11] studied a group of 35 euthyroid children with HT ( $n=23$ with goiter) during a median duration of L-T4 treatment of 2.8 years and reported a reduction in the median thyroid volume from 2.5 SDS at baseline to 1.8 SDS at the final ultrasound examination. In euthyroid children without goiter, no change was noticed. The authors speculated that the reduction in thyroid size was more pronounced in enlarged thyroid glands than in normal-sized ones. Scarpa et al. [24] studied 50 euthyroid nongoitrous children and adolescents with HT for 2 years: 25 were randomized to receive $\mathrm{L}-\mathrm{T} 4$, and 25 did not receive treatment. The children with L-T4 had a further reduction in the thyroid volume after 2 years, whereas the thyroid size increased without L-T4 treatment. Özen et al. [5] reported on a large number of patients with HT, but only 8 of 18 patients with goiter were treated with L-T4 at presentation. During follow-up ultrasounds, the size of the thyroid gland was found to be decreased or reverted to normal size in 7 patients, whereas no remarkable decrease was found in the group not receiving therapy. The latter finding is in agreement with data reported from Thailand, where the goiter size remained unchanged during longterm follow-up of euthyroid children with HT not treated with L-T4 [10]. However, the comparability of the reported results is complicated due to various factors, such as small patient groups, different study design, and different methods of thyroid size measurement, and/or differences in reference data used for the interpretation of the results.

The mean thyroid volume of our euthyroid patients with HT treated with L-T4 was 2.5 SDS at the start and
1.3 SDS after 36 months. Our untreated comparison group also showed a reduction in thyroid size from 1.6 SDS at enrolment to 1.1 SDS at the end of the 36-month observation period (fig. 2). However, when using the 36-month time point with almost identical thyroid volumes in both groups, the conclusion that L-T4 has no effect on thyroid size is biased due to the small number of patients and the sudden loss of 6 patients in each group from the 30 -month time point. At the 30 -month time point, there are more patients and the thyroid volume follows the evolution at the earlier time points. Our data show a constant decline in the mean thyroid volume from 2.13 SDS at month 12 to 1.12 SDS at month 30 in the L-T4-treated group. The delta thyroid volume was -1.01 SDS, but it was +0.27 SDS in the observation group. Statistically, the change of the delta thyroid volume was significantly different between both groups during the 12and 30 -month time points $(\mathrm{p}<0.05)$. Our data show that the change in the delta thyroid volume is a better parameter to measure outcome than the thyroid volume.

When analyzing the data only longitudinally for the 10 patients in each group, we also found a constant decline in the mean thyroid volume of the L-T4-treated group from the start to the 24-month time point (delta thyroid volume: -0.77 SDS), whereas the mean thyroid volume remained unchanged or slightly increased in the observation group (delta thyroid volume: +0.42 SDS). The change of the delta thyroid volume was significantly different between both groups from the start to the 24-month time point $(\mathrm{p}<0.05)$. The longitudinal data show that the effect of L-T4 therapy on the thyroid volume is limited to the first 2 years.

Our data conform to a study performed according to our protocol in patients with type 1 diabetes mellitus and HT [25]. This study was stopped at month 24 and also found no effect of L-T4 treatment on thyroid function and serum autoantibody levels. In our study, the L-T4 dose was titrated to keep the TSH values within the normal range; accordingly, the dose was decreased in 4 patients and increased in 5. This therapeutic regimen was not associated with any changes in thyroid size and autoantibody levels. At the start of our study, the mean thyroid volume of the euthyroid patients treated with L-T4 was almost identical with that of the group studied by Karges et al. [25] (2.7 SDS at the start). Moreover, the mean thyroid volume reduction of -1.38 SDS after 30 months in our treatment group was in the same range as in the group reported by Karges et al. after 24 months. We also found an increase in the thyroid volume in the observation group at 30 months (delta thyroid volume: +0.23 
SDS). The thyroid volume in the nontreated group reported by Karges et al. increased to +1.1 SDS after 24 months. In both studies, thyroid volume was determined by ultrasound, but different reference groups of iodinesufficient children were used for SDS calculations. For reference, we used the data of the German KIGGS Study [19], whereas Karges et al. [25] used the data of a Berlin cohort of healthy school children published by Liesenkötter et al. [26]. One should also keep in mind that we studied euthyroid children with HT who were otherwise healthy, whereas Karges et al. studied euthyroid patients with HT and type 1 diabetes.

Despite randomization of our patients, the patients in the treatment group had by chance a lower chronological age and a higher prevalence of an enlarged thyroid gland, but the main clinical characteristics of the patients were not different from those reported in other studies $[6,27]$. Our data show that TPOAb remained unchanged during the study period in both groups, whereas $\mathrm{TgAb}$ were lower in the observation group. Our data do not confirm other studies, particularly in adults, where a reduction of antiTPO and anti-Tg levels was reported during L-T4 treatment $[28,29]$. The small amount of our data does not support the speculation that thyroid antibodies can be used as predictive factors for the course of the disease $[7,30]$. The proportion of our children (38\%) who became subclinically hypothyroid in the observation group was comparable to other reported values of $12.5 \%$ [5] and $42 \%$ [24].

Unfortunately, our study ended prematurely (after 36 instead of 60 months) with only one third of the enrolled patients meeting the protocol. We are aware that our results could be biased by the small number of patients. Therefore, the results of the study should be carefully interpreted. Our data show that the delta thyroid volume change is a better parameter to measure outcome than thyroid volume and that the effect of L-T4 treatment on thyroid volume change depends on the time points chosen. Taking all data together, we conclude that L-T4 treatment does decrease the thyroid volume, but the effect is limited to a definite time period.

\section{Acknowledgements}

We would like to thank our patients and their parents for participating in the study.

\section{Disclosure Statement}

The authors have nothing to disclose.

\section{References}

1 McGrogan A, Seaman HE, Wright JW, de Vries CS: The incidence of autoimmune thyroid disease: a systematic review of the literature. Clin Endocrinol (Oxf) 2008;69:687-696.

$\checkmark 2$ Rallison ML, Dobyns BM, Keating FR, Rall JE, Tyler FH: Occurrence and natural history of chronic lymphocytic thyroiditis in childhood. J Pediatr 1975;86:675-682.

3 Kaloumenou I, Mastorakos G, Alevizaki M, Duntas LH, Mantzou E, Ladopoulos C, Antoniou A, Chiotis D, Papassotiriou I, Chrousos GP, Dacou-Voutetakis C: Thyroid autoimmunity in schoolchildren in an area with longstanding iodine sufficiency: correlation with gender, pubertal stage, and maternal thyroid autoimmunity. Thyroid 2008;18:747-754.

4 de Vries L, Bulvik S, Phillip M: Chronic autoimmune thyroiditis in children and adolescents: at presentation and during long-term follow-up. Arch Dis Child 2009;94:33-37.

5 Özen S, Berk O, Simsek DG, Darcan S: Clinical course of Hashimoto's thyroiditis and effects of levothyroxine therapy on the clinical course of the disease in children and adolescents. J Clin Res Pediatr Endocrinol 2011;3: 192-197.
6 Wasniewska M, Corrias A, Salerno M, Mussa A, Capalbo D, Messina MF, Aversa T, Bombaci S, De Luca F, Valenzise M: Thyroid function patterns at Hashimoto's thyroiditis presentation in childhood and adolescence are mainly conditioned by patients' age. Horm Res Paediatr 2012;78:232-236.

7 Radetti G, Maselli M, Buzi F, Corrias A, Mussa A, Cambiaso P, Salerno M, Cappa M, Baiocchi M, Gastaldi R, Minerba L, Loche S: The natural history of the normal/mild elevated TSH serum levels in children and adolescents with Hashimoto's thyroiditis and isolated hyperthyrotropinaemia: a 3-year followup. Clin Endocrinol (Oxf) 2012;76:394-398.

-8 De Luca F, Santucci S, Corica D, Pitrolo E, Romeo M, Aversa T: Hashimoto's thyroiditis in childhood: presentation modes and evolution over time. Ital J Pediatr 2013;39:8.

-9 Chaudhary V, Bano S: Thyroid ultrasound. Indian J Endocrinol Metab 2013;17:219-227.

10 Jaruratanasirikul S, Leethanaporn K, Khuntigij P, Sriplung H: The clinical course of Hashimoto's thryoiditis in children and adolescents: 6 years longitudinal follow-up. J Pediatr Endocrinol Metab 2001;14:177-184.
11 Svensson J, Ericsson UB, Nilsson P, Olsson C, Jonsson B, Lindberg B, Ivarsson SA: Levothyroxine treatment reduces thyroid size in children and adolescents with chronic autoimmune thyroiditis. J Clin Endocrinol Metab 2006;91:1729-1734.

12 Lazarus J, Brown RS, Daumerie C, Hubalewska-Dydejczyk A, Negro R, Vaidya B: 2014 European thyroid association guidelines for the management of subclinical hypothyroidism in pregnancy and in children. Eur Thyroid J 2014;3:76-94.

13 Bona G, Prodam F, Monzani A: Subclinical hypothyroidism in children: natural history and when to treat. J Clin Res Pediatr Endocrinol 2013;5(suppl 1):23-28.

14 Rother KI, Zimmerman D, Schwenk WF: Effect of thyroid hormone treatment on thyromegaly in children and adolescents with Hashimoto disease. J Pediatr 1994;124:599601.

15 Radetti G, Gottardi E, Bona G, Corrias A, Salardi S, Loche S: The natural history of euthyroid Hashimoto's thyroiditis in children. J Pediatr 2006;149:827-832. 
16 Padberg S, Heller K, Usadel KH, SchummDraeger PM: One-year prophylactic treatment of euthyroid hashimoto's thyroiditis patients with levothyroxine: is there a benefit? Thyroid 2001;11:249-255.

17 Aksoy DY, Kerimoglu U, Okur H, Canpinar H, Karaagaoglu E, Yetgin S, Kansu E, Gedik O: Effects of prophylactic thyroid hormone replacement in euthyroid Hashimoto's thyroiditis. Endocr J 2005;52:337-343.

18 Brunn J, Block U, Ruf G, Bos I, Kunze WP, Scriba PC: Volumetric analysis of thyroid lobes by real-time ultrasound (author's translation; in German). Dtsch Med Wochenschr 1981;106:1338-1340.

$\checkmark 19$ Thamm M, Ellert U, Thierfelder W, Liesenkötter KP, Volzke H: Iodine intake in Germany. Results of iodine monitoring in the German health interview and examination survey for children and adolescents (KIGGS) (in German). Bundesgesundheitsblatt Gesundheitsforschung Gesundheitsschutz 2007;50: 744-749.

-20 Johner SA, Thamm M, Stehle P, Nothlings U, Kriener E, Volzke H, Gartner R, Remer T: Interrelations between thyrotropin levels and iodine status in thyroid-healthy children. Thyroid 2014;24:1071-1079.

-21 Kromeyer-Hauschild K, Wabitsch M, Kunze D, Geller F, Geiá HC, Hesse V, von Hippel H,
Jaeger U, Johnsen D, Korte W, Menner K, Müller G, Müller JM, Niemann-Pilatus A, Remer T, Schaefer F, Wittchen HU, Zabransky S, Zellner K, Ziegler A, Hebebrand J: Perzentile für den Body-Mass-Index für das Kindesund Jugendalter unter Heranziehung verschiedener Deutscher Stichproben (percentiles of body mass index in children and adolescents evaluated from different regional German studies). Monatsschr Kinderheilkd 2001;149:807-818.

22 Doeker B, Reinehr T, Andler W: Autoimmune thyroiditis in children and adolescents: clinical and laboratory findings in 34 patients (in German). Klin Padiatr 2000;212:103-107.

23 Dötsch J, Hau M, Heidemann P, Rabl W, HU T, Dörr H: Verlauf, Therapie und Komorbidität bei Hashimotothyreoiditis im Kindesalter. Monatsschr Kinderheilkd 2003;151:4.

24 Scarpa V, Kousta E, Tertipi A, Vakaki M, Fotinou A, Petrou V, Hadjiathanasiou C, Papathanasiou A: Treatment with thyroxine reduces thyroid volume in euthyroid children and adolescents with chronic autoimmune thyroiditis. Horm Res Paediatr 2010;73:6167.

25 Karges B, Muche R, Knerr I, Ertelt W, Wiesel T, Hub R, Neu A, Klinghammer A, Aufschild J, Rapp A, Schirbel A, Boehm BO, Debatin KM, Heinze E, Karges W: Levothyroxine in euthyroid autoimmune thyroiditis and type 1 diabetes: a randomized, controlled trial. J Clin Endocrinol Metab 2007;92:1647-1652.

26 Liesenkötter KP, Kiebler A, Stach B, Willgerodt $\mathrm{H}$, Grüters A: Small thyroid volumes and normal iodine excretion in Berlin schoolchildren indicate full normalization of iodine supply. Exp Clin Endocrinol Diabetes 1997; 105(suppl 4):46-50.

27 Skarpa V, Kousta E, Tertipi A, Anyfandakis K, Vakaki M, Dolianiti M, Fotinou A, Papathanasiou A: Epidemiological characteristics of children with autoimmune thyroid disease. Hormones (Athens) 2011;10:207-214.

-28 Mariotti S, Caturegli P, Piccolo P, Barbesino G, Pinchera A: Antithyroid peroxidase autoantibodies in thyroid diseases. J Clin Endocrinol Metab 1990;71:661-669.

-29 Romaldini JH, Biancalana MM, Figueiredo DI, Farah CS, Mathias PC: Effect of 1-thyroxine administration on antithyroid antibody levels, lipid profile, and thyroid volume in patients with Hashimoto's thyroiditis. Thyroid 1996;6:183-188.

30 Hegedus L, Hansen JM, Feldt-Rasmussen U, Hansen BM, Hoier-Madsen M: Influence of thyroxine treatment on thyroid size and antithyroid peroxidase antibodies in Hashimoto's thyroiditis. Clin Endocrinol (Oxf) 1991;35: 235-238.

\section{Erratum}

In the article by Kim et al., entitled 'Clinical and endocrine features of two Allan-HerndonDudley syndrome patients with monocarboxylate transporter 8 mutations' [Horm Res Paediatr 2015;83:288-292, DOI: 10.1159/000371466], the following errors occurred:

1. 'p.I114N' should be 'p.I188N' throughout the text.

2. In figure 1a, 'c.341T>A (p.IIe114Asn)' should be 'c.563T >A (p.Ile188Asn)', and in the accompanying legend as well as in the Case Reports section, 'c.341T>A (p.I114N)' should be 'c.563T >A (p.I188N)'.

3. 'Heterozygous' should be 'hemizygous' throughout the text.

Please excuse any inconveniences caused. 